approach to the exumination of the eytochemical correlates of transneuronal atrophy which has the advantage of permitting simultaneous observation of control (normal) and experimental (atrophied) neurones side by side.

\section{Carl Kupeer}

Howe Laboratory of Ophthalmology,

Harvard University Medical Sehool,

Massachusetts Eye and Ear Infirmary, Boston. Mass.

${ }^{2}$ Cook, W. H., Walker, J. H., and Barr, M. L., J. Comp. Neurol., 84, 267 (1951).

\section{Glycogenolysis in Aliquots of Glycogen Bodies of the Chick}

Previous attempts to change the glycogen concentration in the glycogen body of birds failed ${ }^{1-4}$ except for a few cases in which it was slightly increased ${ }^{5,6}$. In the experiments recorded here the effect of tissue homogenates on the polysaccharide of the glycogen body of the chick was examined. Glycogen bodies of chicks 1-4 weeks old were isolated, woighed on a Roller Smith torsion balance and homogenized in glass tissue-grinders. Ringer's solution, or isotonic sodium chloride buffered with $0.01 \mathrm{M}$ phosphate to $p H \mathbf{7 \cdot 4}$, was added to the homogenate in the proportion of $1 \mathrm{ml}$. per mg of tissue. Twenty-four aliquots of $1 \mathrm{ml}$. were then prepared from the homogenate and were divided into 4 groups of 6 each. Ringer's solution $(0.2 \mathrm{ml}$.) was added to the aliquots of one group and $0.2 \mathrm{ml}$ of tissue homogenate (containing $20 \mathrm{mg}$ of chick skeletal muscle, liver or brain) to the others. To the samples of the first group, in 2 series of experimonts, ATP, $\mathrm{DPN}^{+}$and glucose-6-phosphate (1 mg. each) wore added. Two aliquots of each group were extracted ${ }^{7}$ for glycogen immediately, two after $4 \mathrm{~h}$ and 2 after $24 \mathrm{~h}$ of incubation at room temperature $\left(70^{\circ}\right.$ F.). Glycogen was assayed colorimetrically by the anthrone method $^{8}$.

In the first group of aliquots, containing only homogenate of glycogen body, 25 per cent of the polysaccharide was destroyed ir the 24-h incubation (Table 1). Addition of ATP, DPN and glucose-6-phosphate (first and second series) had no effect. In the 3 other groups, to which homogenates of other tissues were added, the breakdown of glycogen was greater. In the presence of skeletal muscle homogenate more than 75 per cent of the initial glycogen was destroyed during the 24-h incubation. Brain homogenate was the least glycogenolytic of the 3 homogenates studied.

An analysis of variance of the data of Table I reveals that the time differences in each group and the difforences between the 4 groups are statistically significant.

The results obtained indicate that hydrolysis of the glycogen body polysaccharide is increased by homo- genates of other tissues (muscle, liver and brain), suggesting that it is of the same nature as that in these tissues. Bloom et al. ${ }^{9}$ and Russell and Bloom ${ }^{10}$ distinguish in liver and muscle a trichloroacetic acid (TCA) soluble fraction of glycogen (free glycogen) and a TCA insoluble fraction (bound glycogen). In the glycogen body all the glycogen is extractable with cold trichloroacetic acid ${ }^{4}$. This, however, does not mean that the polysaccharide in the glycogen body is different from that of liver and skeletal muscle. According to Hanson, Schwartz and Barker ${ }^{11}$ the amount of the so-called bound glycogen (the TCA insoluble fraction) depends on the amount of protein precipitated. The glycogon body is extremely poor in tissue protein; the precipitate in a TCA extract and the amount of bound glycogen would be, consequently, negligible.

The relatively low rate of glycogen hydrolysis in aliquots of glycogen body alone could not be attributed to the lack of phosphorus; the addition of ATP, DPN and glucose-6phosphate was without any effect. Similarly, the presence of an inhibitor would appear to be ruled out, since then muscle or liver homogenate would be expected to have no effect. The results suggest that the glycogen body is relatively poor in glycogenolytic enzymes. In favour of this hypothesis is also the fact that the cells in the glycogen body, almost entirely filled with glycogen, are poor in cytoplasm and contain only a few mitochondria ${ }^{12}$. This, perhaps, explains the low glycogenolytic activity in the glycogen body.

\section{A. M. Lervold}

J. Szepsenwol

Department of Anatomy,

University of Puerto Rico School of Medicine.

${ }_{1}^{1}$ Terni, T., Arch. Ital. Anat. Embryologia, 21, 55 (1924).

${ }^{2}$ Watterson, R. L., J. Morphol., 85, 337 (1949).

${ }^{3}$ Szepsenwol J., Fed. Froe., 12, 141 (1953).

4 Szepsenwol, J., and Michalski, J. V., Amer. J. Physiol., 163, 624 (1951).

"Hazelwood, R. L., Hazelwood, B. S., and McNary, W. F., Endocrinology. 71, 334 (1962).

${ }^{6}$ Snedecor, J. G., King. D. B., and Henrikson, R. C., Gener. and Comp. Endocrinol., 3,176 (1963).

7 Good C. A., Kramer, H., and Somogyi, M., J. Biol. Chem., 100, 485 (1933).

8 Durham, W. F., Bloom, W. L., Lewis, G. T., and Mandel, E. E., Pub. Health Rep., 65, 670 (1950).

${ }^{9}$ Bloom, W. L., Lewis, G. T., Schumpert, M. Z., and Shen, T. M., J. Biol. Chem., 188, 631 (1951).

${ }^{10}$ Russell, J. A., and Bloom, W. L., Amer. J. Physiol., 183, 345 (1955).

${ }^{i s}$ Hanson, R. W., Schwartz, H. S., and Barker, S. B., Amer. J. Physiol., $198,800(1960)$

13 Revel, J. P., and Napolitano, L., Anat. Rec., 136, 264 (1960).

\section{Inhibitory Effects of Cstrogens on Augmented Activity of Endometrial Carbonic Anhydrase caused by $4,4^{\prime}$ - Methylenedianiline}

Previous work ${ }^{1}$ has shown that $4,4^{\prime}$-methylenedianiline causes an increase in the endometrial carbonic anhydrase when administered to rabbits. The mechanism under-

Table 1. Percentage of Glycogen in Aliquots of grycogen Body of the Chick after Variods Hotrs of INCUbation with Homogenates of Thele 1. PERCENTAL MUSCLE, LIVRR OR BRAIN

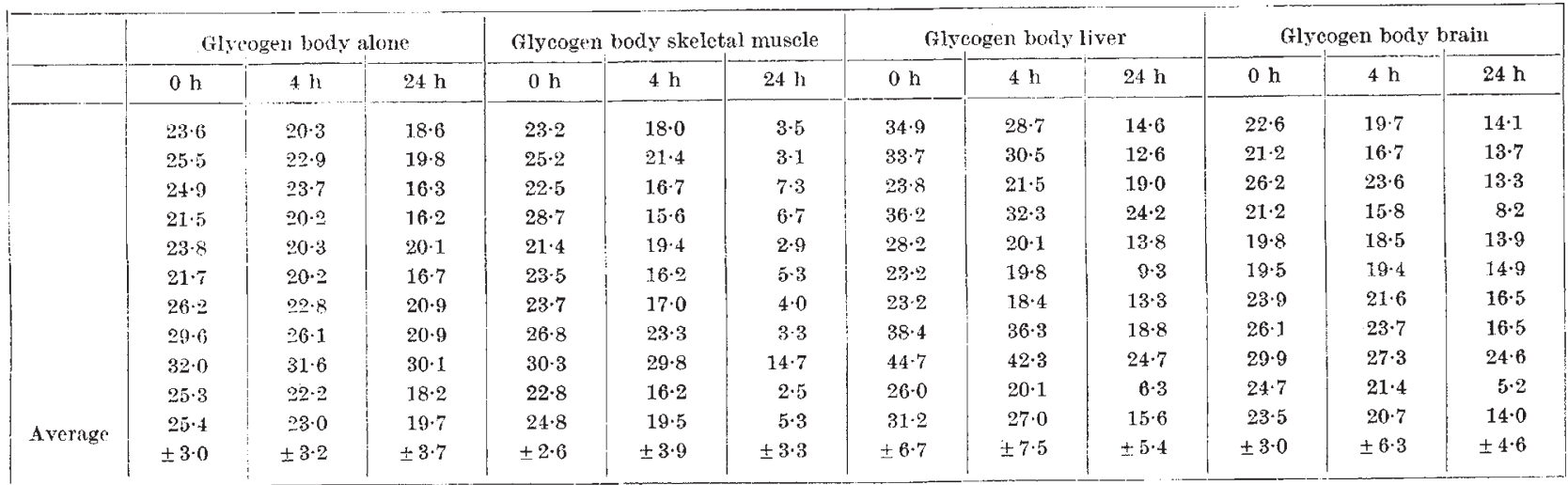

